\title{
RELAÇÃO ENTRE VEGETAÇÃo E PEDOFORMAS NA MATA DO PARAÍSO, MUNICÍPIO DE VIÇOSA, MINAS GERAIS ${ }^{1}$
}

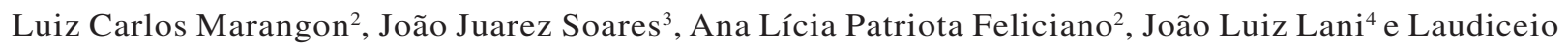
Viana Matos $^{5}$

\begin{abstract}
RESUMO - A Mata do Paraíso, em Viçosa, MG, é classificada como Floresta Estacional Semidecidual em estado avançado de regeneração. Na Zona da Mata de Minas Gerais predominam os Latossolos Vermelho-Amarelos e esta classe também é a mais recorrente na região de Viçosa. São solos, na sua grande maioria de baixa fertilidade natural. Dessa forma, procurou-se associar características dos solos numa topossequência estratificada em geoambientes ou pedoformas, denominados de Plano, Encosta, Ravina e Topo. Para isso, coletaram-se amostras de solos dentro de 40 parcelas, as mesmas utilizadas para caracterizar a vegetação. As amostras de solos foram retiradas nas profundidades de 0 a $20 \mathrm{~cm}, 20$ a $50 \mathrm{~cm}$ e de 50 a $100 \mathrm{~cm}$, em três pontos diferentes de cada parcela. Nas amostras de solos, efetuou-se a análise textural (TFSA), bem como o pH, carbono orgânico total, Ca, Mg, Al, K e P disponível e remanescente. A partir dos resultados calcularam-se a soma de bases (SB), a capacidade de troca catiônica total (T) e efetiva (t), a saturação por bases (V) e a saturação por Al (m). Considerando-se a vegetação como indicador ambiental, verificaou-se um maior número de espécies na Encosta (104), mas com plantas de menor porte e, em seguida, na Ravina (28), com árvores com DAP e alturas bem maiores. Na Encosta, o solo é mais pobre em nutrientes do que na Ravina e muito mais propenso à erosão laminar. Assim, supõe-se que a opção da natureza seria pela diversidade para melhorar a eficiência da reciclagem, coisa que as espécies estariam fazendo em seu próprio benefício. A pedoforma Topo apresenta muita restrição em nutrientes, o que limita, em parte, não somente indivíduos de tamanho e diâmetros maiores, bem como a própria diversidade de espécies. As espécies pioneiras, nesse caso, teriam papel fundamental na manutenção ou na "formação" da fertilidade desse geoambiente. Pela textura, foi possível separar nas três profundidades dois grupos: Plano e Topo apresentam texturas mais homogêneas e Ravina e Encosta mais heterogêneas.
\end{abstract}

Palavras-chave: Topossequência; Índice de diversidade; Vegetação secundária.

\section{RELATIONSHIP BETWEEN VEGETATION AND LANDFORMS IN THE MATA DO PARAÍSO, VIÇOSA, MINAS GERAIS}

\begin{abstract}
The Mata do Paraíso is originated in regeneration, making up secondary vegetation whose typology is Semidecídua Estacional Forest. In the Zona da Mata from Minas Gerais State, the Latosols predominate and this category is, also, the most present in the Viçosa's region where the soils are, generally, nutritive poor. Thus, it was looked for associating some characteristics of soils from "Mata do Paraíso" in specified order to relationate them with the evolution of different kinds of toposequences, presents in the studied area, and the local arboreous vegetation. Samples were gathered inside the 40 parcels, the same ones utilized for the vegetation study. Samples weretaken away from 0 to $20 \mathrm{~cm}, 20$ to $50 \mathrm{~cm}$ and 50 to $100 \mathrm{~cm}$ of depth in three different points. TFSA textural analysis of the soil was performed, as well as, density of soil, $\mathrm{pH}$, total organic carbonic, $\mathrm{Ca}, \mathrm{Mg}, \mathrm{Al}, \mathrm{K}$ and $\mathrm{P}$. Based on the results achieved, the sum of the basis was calculated
\end{abstract}

\footnotetext{
${ }^{1}$ Recebido em 28.09.2011 aceito para publicação em 12.05.2013.

${ }^{2}$ Departamento de Ciência Florestal, Universidade Federal Rural de Pernambuco, PE, Brasil. E-mail: <marangon@dcfl.ufrpe.br> e $<$ licia@dcfl.ufrpe.br>.

${ }_{3}^{3}$ Departamento de Botânica, Universidade Federal de São Carlos, UFSCar, SP, Brasil. E-mail: <juares@ufscar.br>

${ }^{4}$ Departamento de Solos, Universidade Federal de Viçosa, MG, Brasil. E-mail: <lani@ufv.br>.

${ }^{5}$ Engenheiro Agrônomo, INCRA, BA, Brasil. E-mail: <laudimatos@yahoo.com.br>.
} 


\begin{abstract}
$(S P)$, the cationic change capacity $(T)$ and effective ( $t)$, saturating for basis $(V)$ and saturating for Al. The remainders $P$ were also determinated. Using the vegetation as the best ambient indicator, it can be perceived more species at the hillside, but with small plants and, following, the Ravine, with bigger trees. On the Hillside, the soil is poorer than the Ravine's and more subordinate to laminar erosion. In this case, the natures' option would be increase the recycledefficiency by the diversity, what the species would be doing by its self benefit. The Top is too poor, that limits individuals of bigger size and diameter, as well as its self diversity. The pioneer species, in this case, would have a fundamental role in maintaining or in the "formation" of this soil fertility. The texture, it is perceived that is possible separating on the 3 depths, 2 ambient groups: on Plan e the Top present a texture more homogeneous and Ravine and Hillside more heterogeneous.
\end{abstract}

Keywords: Toposequence; Diversity rate; Secondary vegetation.

\section{INTRODUÇÃO}

Nas regiões montanhosas, como a da Zona da Mata de Minas Gerais, é comum a formação de diversos ambientes e cada um deles pode propiciar condições para o desenvolvimento de vegetação. Isso é importante, especialmente, no momento em que o uso da terra de forma sustentável é cada vez mais necessário e também na recuperação da vegetação nativa. Essa região encontra-se no domínio dos Mares de Morros Florestados, onde as Florestas Semidecíduas ocorrem em sua grande maioria (VELOSO et al., 1991).

Os solos são muito intemperizados, com baixos teores de nutrientes e apresentam, geralmente, horizonte C profundo. Predominam os Latossolos, que na sua maioria são resistentes à erosão, apesar de predominarem declives acentuados (relevo forte ondulado e montanhoso). Os deslizamentos de terra, em alguns locais, são comuns em razão da ocorrência de um horizonte $\mathrm{B}$ argiloso e estreito e o horizonte $\mathrm{C}$ muito profundo, pouco coerente e muito siltoso, com grandes lâminas de caulinita (PINTO, 1971). Nesse caso, o solo é classificado como Cambissolo Háplico (EMBRAPA, 2006). Os Latossolos Vermelho-Amarelos predominam na região, principalmente na parte montanhosa, e são, muito pobres em nutrientes (REZENDE, 1971; CORRÊA, 1984).

As características específicas do solo na pedopaisagem, por exemplo, em topossequência onde envolvem os ambientes (pedoformas) denominados Plano, Encosta, Ravina e Topo, associados às características da vegetação arbórea, permitem avaliar ocorrências preferenciais de determinadas espécies em ambientes distintos (BIGARELLA et al.; 1975; CERQUEIRA, 1995; ARAÚJO et al., 2006). Assim, a identificação de espécies adaptadas a cada geoambiente e a ação no processo de recuperação dessas áreas de forma específica é facilitada e com maiores condições de sucesso. As propriedades físicas, químicas e mineralógicas do solo e o relevo influenciam no comportamento e desenvolvimento das espécies arbóreas, por meio da disponibilidade de nutrientes e água (RESENDE et al., 2002). Nesse caso, os conhecimentos desses fatores ambientais contribuirão para o entendimento da ocorrência e ecologia dessas espécies, ao fornecer informações básicas para o manejo sustentável desse tipo de formação florestal na Zona da Mata de Minas Gerais e em outras regiões afins com características semelhantes (PINTO et al., 2005).

Diante disso, o estudo dos solos da Mata do Paraíso foi realizado para Identificar parte do complexo biológico ativo que proporcionou o estabelecimento da vegetação arbórea oriunda de regeneração de espécies florestais nativas formando uma mata secundária. Dessa forma, procurou-se associar algumas características dos solos da Mata do Paraíso com o objetivo específico de relacioná-las com a evolução da cobertura vegetal espontânea da área (espécies presentes, CAP e altura das árvores) nos diferentes pedoambientes (Plano, Encosta, Ravina e Topo).

\section{MATERIAL E MÉTODOS}

A Mata do Paraíso localiza-se no município de Viçosa, Minas Gerais, nas coordenadas de $20^{\circ} 45^{\prime}$ de latitude Sul e $42^{\circ} 51^{\prime}$ de longitude Oeste. A área foi desmatada para cultivo de café e pastagens. Atualmente, encontra-se em plena regeneração. A topossequência estudada foi dividida em quatro ambientes ou pedoformas denominadas de Plano: parte inferior do vale, próximo ao talvegue; Encosta: considerado o terço inferior da encosta, pedoforma convexo-convexa; Ravina: porção mais inclinada, normalmente no terço médio; e Topo: parte superior dos morros, normalmente plana.

Revista Árvore, Viçosa-MG, v.37, n.3, p.441-450, 2013 
Na caracterização dos solos (pedoformas) da Mata do Paraíso, foram coletadas três amostras em cada uma das 40 parcelas, as mesmas foram utilizadas no estudo de estrutura fitossociológica da vegetação (MARANGON, 1999). Utilizou-se o trado tipo holandês para a coleta das amostras nas profundidades de 0 a $20 \mathrm{~cm}, 20$ a $50 \mathrm{~cm}$ e 50 a $100 \mathrm{~cm}$, em três pontos diferentes das parcelas, formando amostra composta. A análise textural (TFSA) foi efetuada por meio de peneiramento via úmida, e as frações silte e argila foram separadas pelo método da pipeta. A dispersão do solo foi promovida por agitação em coqueteleira, em meio alcalino, sem se proceder à oxidação prévia da matéria orgânica (EMBRAPA, 1997).

Na determinação da cor do solo utilizou-se o sistema comparativo com a carta de campo, tanto para o solo úmido quanto para o solo seco (MUNSELL, 1994). A densidade das partículas foi obtida pelo método do balão volumétrico e a do solo, pelo método do torrão parafinado (EMBRAPA, 1997). O pH em água foi determinado mediante a utilização das proporções 1:2,5 (v/v) de solo:solução. O carbono orgânico total foi determinado pelo método de Walkley-Black. O Ca, Mg e Al foram extraídos por solução de $\mathrm{KCl} 1 \mathrm{~mol} \mathrm{~L}^{-1}$, enquanto K e P foram extraídos pelo extrator Mehlich 1. A acidez potencial $(\mathrm{H}+\mathrm{Al})$ foi determinada conforme a Embrapa (1997). Os teores de Ca, Mg e Al foram determinados por espectrometria de absorção atômica. O fósforo foi determinado por fotocolorimetria e K por fotometria de chama. A partir dos resultados, calcularam-se a Soma de Bases (SB), a Capacidade de troca catiônica total (T) e efetiva (t), a saturação por bases (V) e a saturação por $\mathrm{Al}(\mathrm{m})$. O P remanescente foi determinado segundo Alvarez et al. (2000).

Para identificação dos minerais da fração argila, utilizou-se a técnica de difração de raios-X (WITTIGE ALLARDICE, 1986). Inicialmente, realizaram-se a oxidação da matéria orgânica das amostras de solo (ANDERSON, 1963; JACKSON, 1979) e a separação da fração argila (EMBRAPA, 1997), seguida da desferrificação dessas partículas pelo citrato-ditionito (COFFIN, 1963). Foram preparadas lâminas com amostras orientadas naturais (sem desferrificação) e desferrificadas solvatadas com $\mathrm{K} \mathrm{e} \mathrm{Mg}$, conforme a necessidade, e posteriormente irradiadas no intervalo

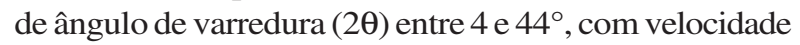
do goniômetro de $2^{\circ} 2 \theta \mathrm{min}^{-1}$, utilizando-se radiação
CoKa. A identificação dos minerais de argila a partir dos difratogramas foi realizada conforme Chen (1977) e Besoain (1985).

\section{RESULTADOS}

Embora as análises físicas, químicas e mineralógicas tenham sido efetuadas nos diferentes ambientes (pedoformas) e em diversas profundidades, sabe-se dispensável que esse tipo de estudo compartimentalizado nem sempre representa o conjunto de interações das condições de campo. Nesta análise, procurou-se verificar como a "fertilidade", no seu conjunto representada pelos teores de $\mathrm{Ca}, \mathrm{Mg}, \mathrm{K}$, $\mathrm{P}$, valor S, e carbono orgânico e a interação entre esses e outros fatores (Figuras 1, 2 e 3) influenciam no comportamento da vegetação em diferentes pedoformas (topossequência), bem como se a textura influenciou na disponibilidade de nutrientes e de água para as plantas.

A vegetação apresentou-se como o melhor indicador das condições ambientais nas diferentes pedoformas. Pode-se perceber o maior número de espécies no ambiente Encosta (104 espécies), mas com plantas de menor porte, e em seguida a Ravina (78 espécies), com árvores de porte bem maior (mais de duas vezes, tanto no CAP quanto na altura) (Tabela 1).

Pelos dados granulométricos de cada ambiente e em diferentes profundidades, podem-se avaliar aspectos quanto à intensidade relativa da erosão, bem como a estabilidade mineral e potencial dos solos que pode ser comprovada pela avaliação da mineralogia da fração argila pelos raios-X (Figura 4), em que os tipos de minerais podem indicar o estágio de intemperismo dos solos em cada ambiente e o potencial deles na liberação de nutrientes.

\section{DISCUSSÃO}

O solo é um dos melhores estratificadores de ambientes. Ele interage com diversos outros compartimentos, como a litosfera, hidrosfera, biosfera e atmosfera (RESENDE; REZENDE, 1983). Mas a vegetação em algumas situações, principalmente em seu estado natural ou em processo de regeneração, pode ser o melhor indicador das condições ambientais que podem favorecer para o seu melhor estado vegetativo e reprodutivo (RESENDE et al., 2007), pois, nesse caso,

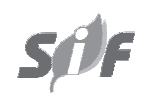

Revista Árvore, Viçosa-MG, v.37, n.3, p.441-450, 2013 

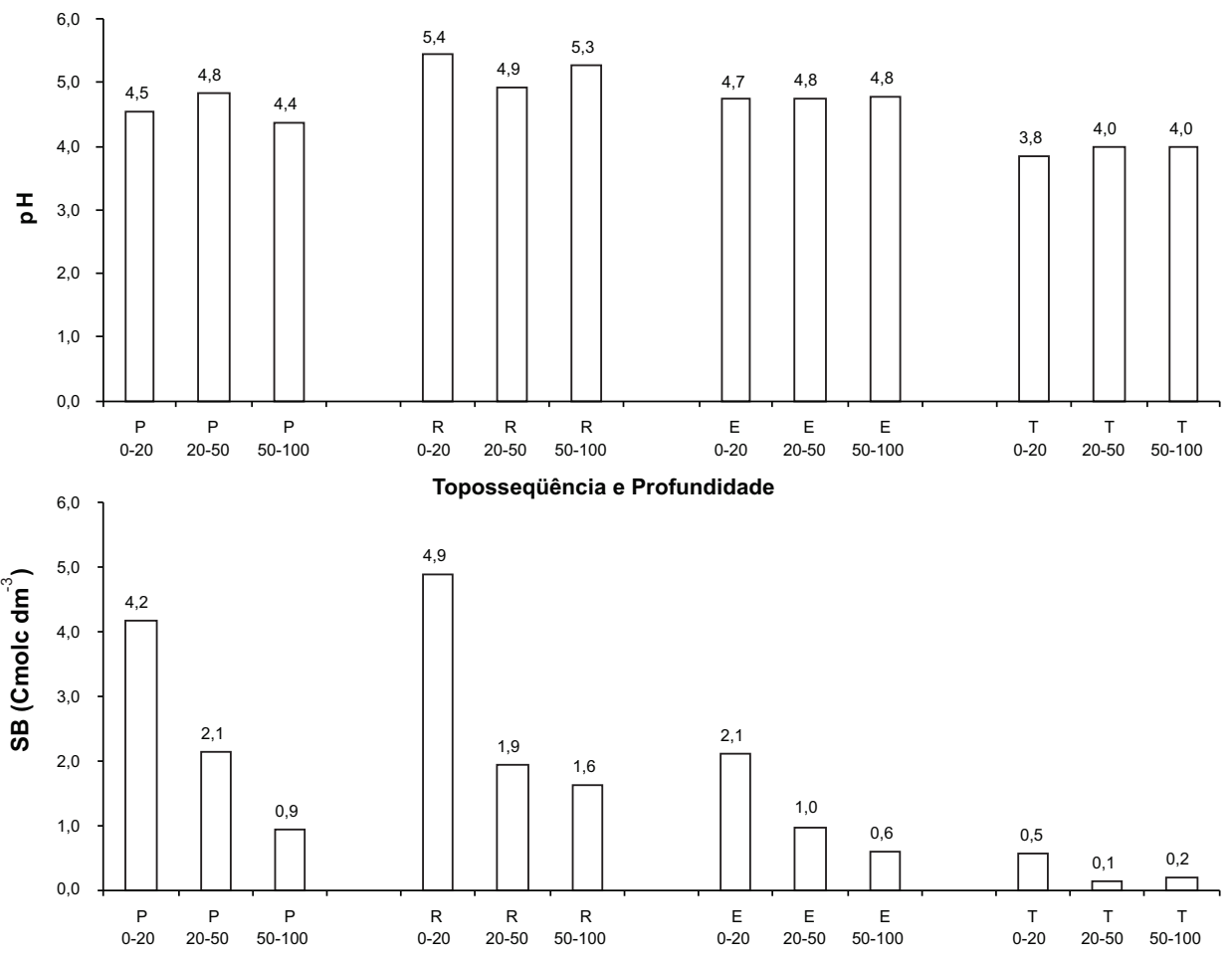

Toposseqüência e Profundidade

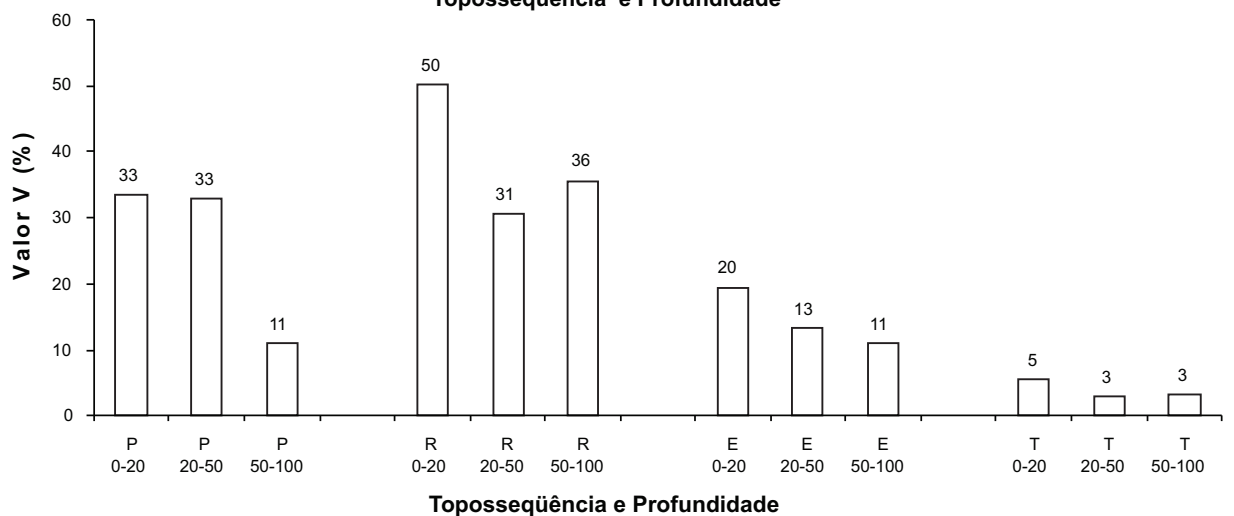

Figura 1 - pH, soma de bases e saturação por bases das diferentes topossequências $(\mathrm{P}=$ plano, $\mathrm{R}=$ ravina, $\mathrm{E}=\mathrm{encosta}$, $\mathrm{T}=$ topo) e profundidades $(0-20,20-50$ e 50-100 cm) da Mata do Paraíso, Viçosa, MG.

Figure 1 - pH, sum of bases and base saturation of toposequences different (P: plane, R: ravine, E: hillside, T: top) and depths (0-20, 20-50,50-100cm), the Mata do Paraíso, Viçosa, MG.

há um conjunto de fatores que não são mensuráveis nos estudos compartimentalizados. No caso da vegetação, pode-se simplificar que os fatores mais importantes para ela são: água, nutrientes e radiação solar (fotossíntese). Os outros, como pragas e doenças, estão nas condições naturais, associados a estes (RESENDE et al., 2002, 2007).
Nesta análise, procurou-se verificar como a "fertilidade", no seu conjunto representada pelos teores de Ca, Mg, K, P, valor S e carbono orgânico e a interação entre estes e outros fatores não mensuráveis (Figuras 1, 2 e 3), influencia no comportamento da vegetação em diferentes pedoformas (topossequência) na região da Mata Atlântica, bem como, se a textura e a mineralogia

Revista Árvore, Viçosa-MG, v.37, n.3, p.441-450, 2013 

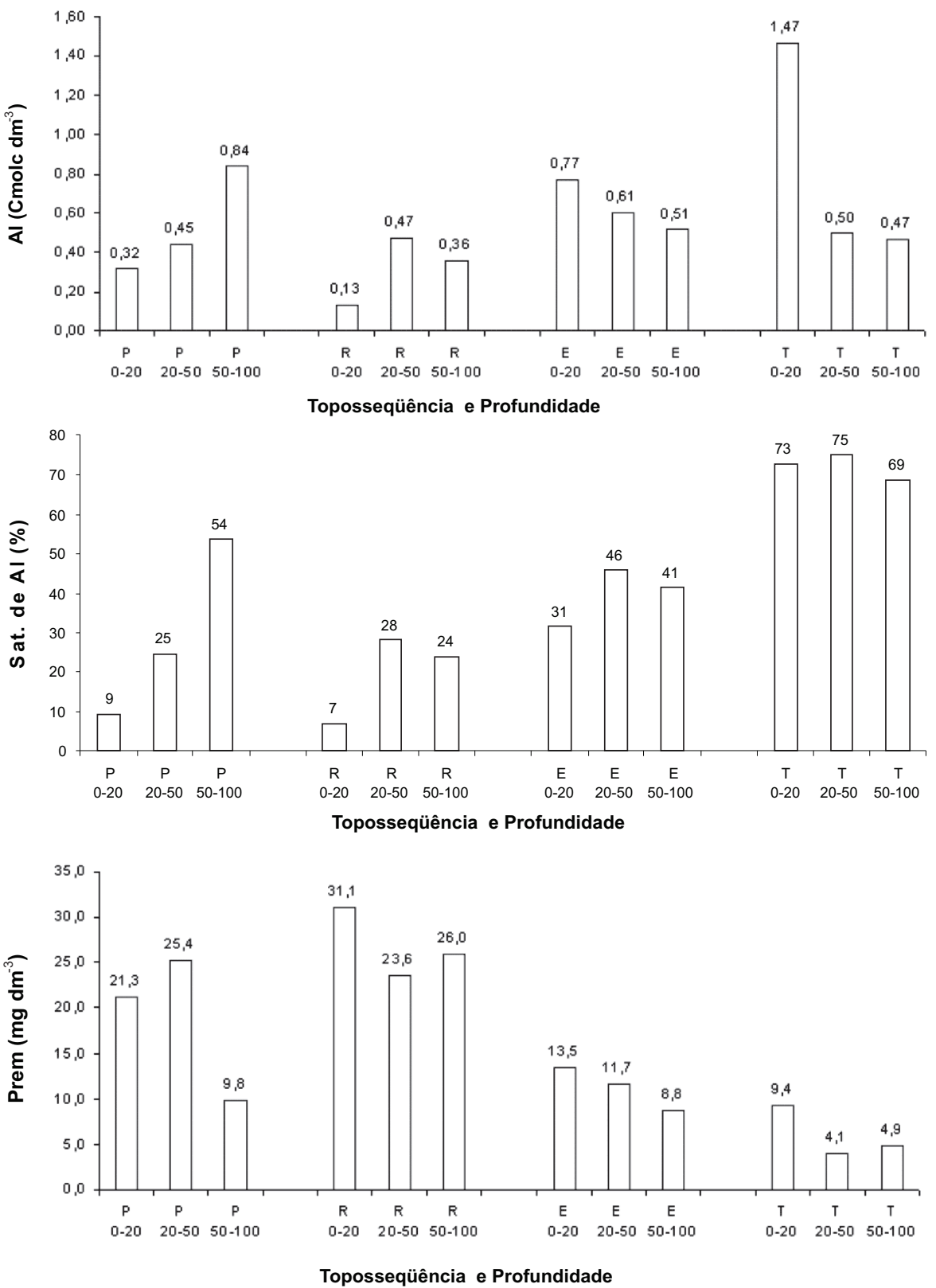

Figura 2 - Al trocável, saturação de alumínio e fósforo remanescente das diferentes topossequência (P: plano, R: ravina, E: encosta, T: topo) e profundidades $(0-20,20-50$ e 50-100 cm) da Mata do Paraíso, Viçosa, MG.

Figure 2-Al, aluminon saturation and phosphorus balance of different environments ( $P$ : plane, $R$ : ravine, E: hillside, T: top) and depths (0-20, 20-50 e 50-100 cm) of the Mata do Paraíso, Viçosa, MG.

têm influência na disponibilidade hídrica e de nutrientes para as plantas.

Ao usar a vegetação como indicador interativo das condições ambientais nas diferentes pedoformas, pode-se perceber (Tabela 1) maior número de espécies vegetais no ambiente Encosta (104 espécies), mas com plantas de menor porte e em seguida a Ravina (78 espécies), com árvores de porte bem maior (mais de duas vezes, tanto no CAP quanto na altura). 

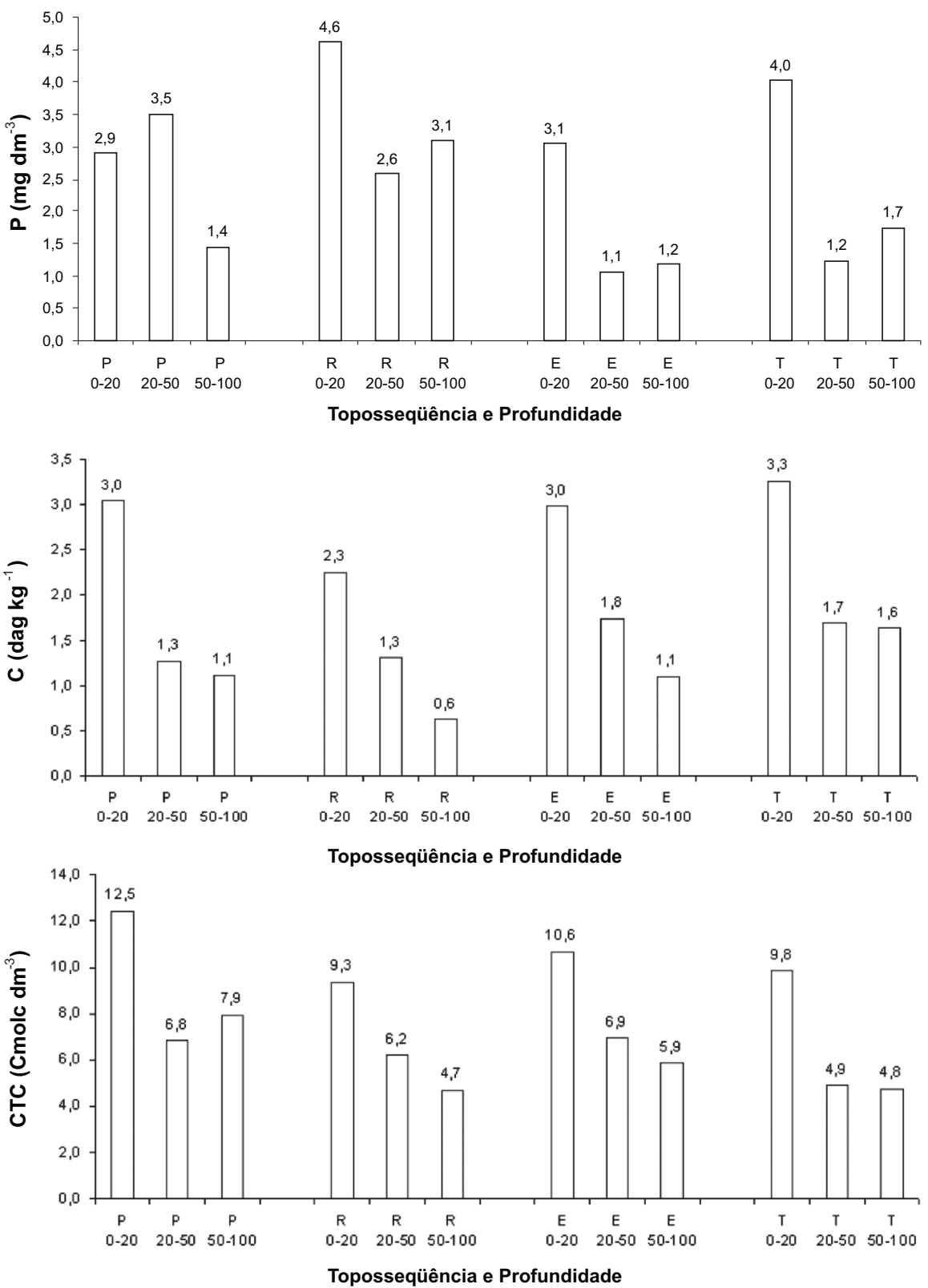

Figura 3 - P disponível, carbono orgânico e CTC das diferentes topossequências (P: plano, R: ravina, E: Hillside, T: topo) e profundidades (0-20, 20-50 e 50-100 cm) da Mata do Paraíso, Viçosa, MG.

Figure 3 -Available phosphorus, organic carbon and CTC of toposequences different (P:plan, R: ravine, E: hillside, T: top) and depths (0-20, 20-50 and 50-100 cm) from the Mata do Paraíso, Viçosa, MG.

Na avaliação dos resultados das análises químicas foi possível verificar, quanto ao $\mathrm{pH}$, soma de bases (Valor S) e saturação por base (Valor V), que há melhoria decrescente das pedoformas Ravina, Encosta e Topo, indicando uma redução da fertilidade do solo na mesma sequência e com maior contraste quanto à Soma de Bases e Valor V. O ambiente Plano não seguiu nenhuma sequência (Figuras 1, 2 e 3 ).

Nessa situação, postula-se que em solos pobres, e com uma precipitação de $1.200 \mathrm{~mm}$, a vegetação atua

Revista Árvore, Viçosa-MG, v.37, n.3, p.441-450, 2013 
seguindo dois padrões básicos: maior número de espécies possíveis, com as suas diferentes necessidades nutricionais e sistema radicular em diferentes profundidades, de forma a manter ao máximo os nutrientes no sistema (ciclagem de nutrientes), garantindo assim, pelo processo evolutivo, a sobrevivência delas. Mas, se o ambiente não é tão pobre em nutrientes, como é o caso da Ravina, que apresenta pedoforma côncavo-côncava e permite concentrar maiores teores de nutrientes e maior disponibilidade de água e com o sinergismo entre esses, isso possibilita, então, uma vegetação com menor número de espécies (menor diversidade) e indivíduos de maiores altura e diâmetro. Nesse caso, pode-se postular que predomina o vigor em relação à diversidade. $\mathrm{O}$ ambiente propicia maior segurança para investir em poucos indivíduos, consequentemente, se estabelece uma menor diversidade.

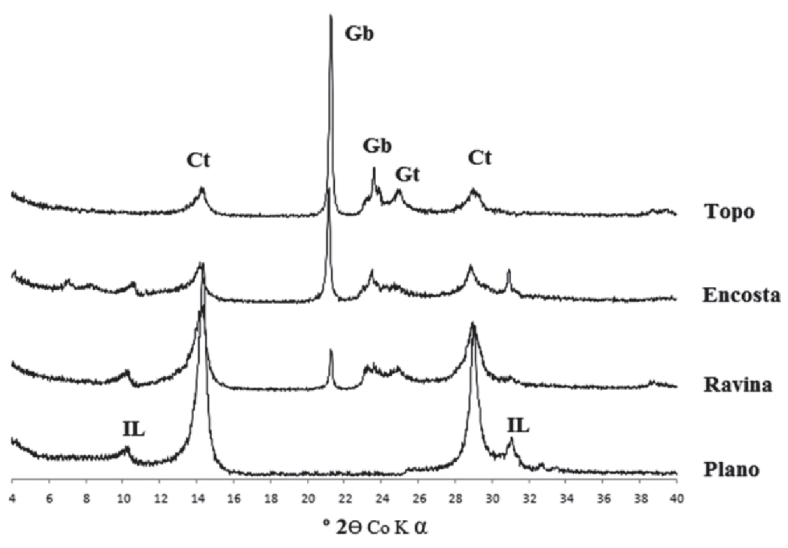

Figura 4 - Difratogramas de raios- $X$ da fração argila dos diferentes ambientes (pedoformas) da Mata do Paraíso, Viçosa, Minas Gerais.

Figure 4 -X-ray diffraction patterns of clay fraction of the different land forms of the Mata do Paraíso, Viçosa, Minas Gerais.
Na encosta, os dados demonstram que o solo é mais deficiente em nutrientes em relação à Ravina e mais sujeito à erosão laminar, em razão da maior declividade.A disponibilidade de nutrientes não é suficiente para propiciar indivíduos mais desenvolvidos em altura e diâmetro. Nesse caso, a opção da natureza seria pela diversidade, para melhorar a eficiência da reciclagem que as espécies estariam fazendo em seu próprio benefício para a sobrevivência de todas (LUIZÃO, 2005; SILVA et al., 2006).

O Topo de todos os ambientes, é o que apresenta os menores índices de fertilidade. Este foi sujeito ao maior intemperismo e é um ambiente que se caracteriza somente por perdas. Não recebe sedimentos e nem é passível de ser renovado pela erosão geológica como a Encosta e a Ravina. Nesse caso, os dados analíticos sugerem que a deficiência de nutrientes é tão intensa que isso condiciona somente indivíduos de altura e diâmetros (Tabela 1) menores, como a própria diversidade. Predominam, então, plantas especializadas em sobrevivência naquele ambiente mais inóspito em relação aos demais. Assim, as espécies pioneiras, então, teriam papel fundamental na manutenção ou na "formação" da fertilidade daquele ambiente, conforme foi observado pelo levantamento das espécies (NAGY, 1998). A própria colonização e a maior diversidade são limitadas pela baixíssima fertilidade desse ambiente. Quanto ao solo, pode ser classificado como álico e apresenta, na camada de $0-20 \mathrm{~cm}$, altos teores de alumínio trocável (Figura 2). Seguindo esse mesmo raciocínio, o índice de diversidade de Shannon e Weaver parece corroborar com o que foi observado (Tabela 1).

No ambiente Encosta, a fertilidade é intermediária (o solo é distrófico), e verifica-se que ocorre maior diversidade de plantas, porém os indivíduos apresentam alturas menores. Na Ravina, no entanto,

Tabela 1 - Número de espécies, CAP médio, altura média e índice de diversidade de Shannon e Weaver (H’) nas diferentes pedoformas.

Table 1 - Number of species, CAP medium, medium height and diversity index Shannon e Weaver ( $\left.H^{\prime}\right)$ indifferent land forms.

\begin{tabular}{|c|c|c|c|c|c|}
\hline Ambientes & Espécies (ud) & $\mathrm{CAP}(\mathrm{cm})$ & Alt.(m) & $\mathrm{H}^{\prime}$ & Observações \\
\hline Plano & 40 & 22,5 & 5,6 & 2,86 & Indiferente \\
\hline Ravina & 78 & 75,5 & 17,5 & 3,38 & Altura e DAP maiores \\
\hline Encosta & 104 & 29,0 & 7,7 & 4,00 & Altura e DAP menores \\
\hline Topo & 61 & 31,6 & 8,0 & 3,65 & Pioneiras predominantes \\
\hline
\end{tabular}


contrasta com melhor fertilidade, porém com menor diversidade de espécies e indivíduos com alturas e diâmetros maiores.

O solo da pedoforma Topo é o que apresenta, em todas as profundidades, os maiores teores de carbono orgânico (Figura 3). Resende et al. (2007) mencionaram que uma das razões do acúmulo de matéria orgânica é o distrofismo acentuado. Os nutrientes limitam a população microbiana que atuaria na decomposição da matéria orgânica, orgânica, contribuindo para o seu acúmulo gradativo. Apesar de apresentar maiores teores de carbono orgânico, a Capacidade de Troca Catiônica (CTC) é relativamente menor quando comparada com a pedoforma Encosta (Figura 3). Supõe-se, nesse caso, que a atividade da argila sobrepõe a da matéria orgânica, em razão de esta ser de baixa qualidade (STEVENSON, 1994; HEYES et al., 2001).

Quanto ao fósforo remanescente, há um declínio dos valores dos ambientes Ravina, Encosta e Topo (Figura 2). Isso demonstra que o solo do Topo é que tem maior capacidade de reter fósforo em relação aos demais ambientes (ALVAREZ et al., 2000). O mesmo não acontece com o fósforo disponível, em que se percebe que, na profundidade de $0-20 \mathrm{~cm}$, a sequência é Ravina maior do que o Topo, e esses teores maiores do que na Encosta, embora a grandeza dos valores quanto à fertilidade não seja representativa. Todos os teores determinados são consideradas em níveis baixos (ALVAREZ et al., 1999).

No que diz respeito à textura, foi possível separar nas três profundidades dois grupos de ambientes: o Plano e o Topo, que apresentam textura mais homogênea e tendente a ser mais argilosa; Ravina e Encosta, textura mais heterogênea e com tendência a ser mais arenosa, com predominância quase que exclusiva de quartzo. O ambiente Ravina é o mais arenoso. Isso indica que a camada superficial está mais sujeita a uma erosão seletiva (laminar), maior saída de argila e também, possivelmente, o recebimento de sedimentos mais grosseiros da parte superior.

Quanto à mineralogia (Figura 4), foi possível identificar na Ravina a presença de caulinita bem cristalizada, mica e goethita. A gibbsita não foi tão evidente. Na Encosta há uma situação intermediária, em que foi possível identificar mica e caulinita esta em estágio intermediário de cristalização e gibbsita (pico bem evidente) e goethita. No Topo, a caulinita ocorre menos cristalizada, havendo também a presença da gibsita e goethita, o que demonstra ser um ambiente altamente intemperizado pela avaliação da fração areia não há nenhuma reserva mineral de nutrientes.

\section{CONCLUSÕES}

O número de espécies, bem como o índice de diversidade de Shannon e Weaver, relacionam-se com a fertilidade dos solos em relação às diferentes pedoformas.

Com a exceção da pedoforma Plano, as áreas restantes apresentam índices de diversidade altos, com a presença de valores mais comuns em Florestas Ombrófilas Densas, como no caso da Encosta.

Acredita-se que a pedoforma propicia condição de fertilidade que, aliada à umidade do solo, promove nas espécies de determinada comunidade uma definição mais rápida dos grupos ecofisiológicos e, consequentemente, nos estádios de sucessão.

\section{REFERÊNCIAS}

ALVAREZ V., V. H. et al. Determinação e uso do fósforo remanescente. Boletim Informativo da Sociedade Brasileira de Ciência do Solo, v.52, n.1, p.27-32, 2000.

ALVAREZ V., V. H. et al. Interpretação dos resultados das análises de solos. In:RIBEIRO, A.C.; GUIMARAES, P.T.G.; ALVAREZ V., V.H. (Ed.). Recomendações para o uso de corretivos e fertilizantes em Minas Gerais: $5^{\text {a }}$ Aproximação. Viçosa, MG: Comissão de Fertilidade do Solo do Estado de Minas Gerais, 1999. p.25-32.

ANDERSON, J. V. An improved pretreatment for mineralogical analysis of samples containing organic matter. Clays and Clay

Minerals,v.10, p.380-388, 1963.

ARAÚJO, F. S.et al. Estrutura da vegetação arbustiva-arbórea colonizadora de uma área degradada por mineração de caulim, Brás Pires, MG. Revista Árvore, v.30, n.1, p.107-116, 2006. 
BESOAIN, E. Mineralogía de arcillas de suelos. San José, Costa Rica: IICA, 1985.1205p.

BIGARELLA, J.; ANDRADE-LIMA, D.; RIEHS, P. Considerações a respeito das mudanças paleoambientais na distribuição de algumas espécies vegetais e animais no Brasil. Anais Academia Brasileira de Ciência, v.47, p.441 - 464, 1975.

CERQUEIRA, A. F. Estratificação de ambientes do município de Venda Nova do Imigrante, ES. 1995. $210 f$. Dissertação (Mestrado em Solos e Nutrição de Plantas) - Universidade Federal de Viçosa, Viçosa, MG,1995.

CHEN, P-Y. Table of key lines in X-ray powder diffraction patterns of mineral in clays and associated rocks. Indiana: Bloomington, 1977. 65p. (Department of Natural Resources Geological Survey Occasional Paper, 21).

COFFIN, D. E. A method for the determination of free iron in soils and clays. Canadian Journal Soil of Science, v.43, n.1, p.7-17, 1963.

CORRÊA, G. F. Modelo de evolução e mineralogia da fração argila de solos do Planalto de Viçosa, MG. Viçosa, MG: Universidade Federal de Viçosa, 1984. 87f.

Dissertação (Mestrado em Solos e Nutrição de Plantas) - Universidade Federal de Viçosa, Viçosa, MG, 1984.

\section{EMPRESA BRASILEIRA DE PESQUISA} AGROPECUÁRIA - EMBRAPA. Manual de métodos de análises do solo. 2.ed. Rio de Janeiro: 1997. 212p.

\section{EMPRESA BRASILEIRA DE PESQUISA} AGROPECUÁRIA - EMBRAPA. Sistema brasileiro de classificação de solos. 2.ed. Rio de Janeiro: 2008. 316p.

HEYES, M. H. B.; CLAPP, C.E. Humic substance: considerations of compositions, aspects of structure and environmental influences. Soil Science, v.166, p.723 - 737, 2001.
JACKSON, M. L. Soil chemical analysis advanced course.2.ed. Madison: University of Wisconsin, 1979.895p.

LUIZÃO, F. J.; NOBRE, C.A.; MANZI, A.O. Projeto LBA; Estudando as complexas interações da biosfera com a atmosfera na Amazônia. Acta Amazônica,v.20, n.2, p.681-708, 2005.

\section{MARANGON, L. C. Florística e} fitossociologia de área de floresta semidecidual visando dinâmica de espécies florestais arbóreas no município de Viçosa, MG. 1999. 147f. Tese (Doutorado em Ecologia e Recursos Naturais) Universidade Estadual Paulista, São Carlos, 1999.

MUNSELL, Soil color sharts. New York: 1994.

NAGY, S. C. S. Avaliação de alguns parâmetros químicos e físicos de um solo submetido a diferentes sistemas de ocupação e a recomposição de mata ciliar. 1998. 134f. Tese (Doutorado em Ecologia e Recursos Naturais) - Universidade Federal de São Carlos, São Carlos,1998.

PINTO, L. V. A. et al.Estudo da vegetação como subsídios para propostas de recuperação das nascentes da bacia hidrográfica do ribeirão Santa Cruz, Lavras, MG. Revista Árvore, v.29, n.5, p.775 - 793, 2005.

PINTO, O. C. B. Formation of a kaolinite from a biotite feldspar gneiss in four strongly weathered soil profiles from Minas Gerais, Brazil. 1971. 133f. Dissertation (Masters in Soil Science) PurdueUniversity, West Lafayette, 1971.

RESENDE, M.et al. Pedologia: Base para distinção de ambientes. 5.ed. Lavras: Universidade Federal de Lavras, 2007. p.322.

RESENDE, M.; LANI, J. L.; RESENDE, S. B. Pedossistemas da Mata Atlântica: considerações pertinentes sobre a sustentabilidade. Revista Árvore, v.26, n.3, p.161-269, 2002.

RESENDE, M.; REZENDE, S. B. Levantamentos de solos: uma estratificação de ambientes. Informe Agropecuário, v.9, n.105, p.3 - 25, 1983.

Revista Árvore, Viçosa-MG, v.37, n.3, p.441-450, 2013 
REZENDE, S. B. Estudo de cronoseqüência em Viçosa - Minas Gerais. 1971. 71f. Dissertação (Mestrado em Solos) Universidade Federal de Viçosa, Viçosa, MG, 1971.

SHANNON, C. E.; WEAVER, W.The mathematical theory of

communication. Champaign, The University of Illinois Press Urbana, 1949.

SILVA, C. E. M. et al. Eficiência no uso dos nutrientes por espécies pioneiras crescidas em pastagens degradadas na Amazônia central. Acta Amazônica,v. 36, n. 4, p.503-512, 2006.
STEVENSON, F. J. Humus chemistry:

Genesis, composition, reactions. 2.ed. New York: John Wiley \& Sons, 1994. 496p.

VELOSO, H. P.; RANGEL FILHO, A. L. R.; LIMA, J. C. A. Classificação da vegetação brasileira adaptada a um sistema universal. São Paulo: Fundação Instituto Brasileiro de Geografia e Estatística, 1991. 123p.

WHITTING, L. D.; ALLARDICE, W. R. X-ray diffraction techniques. In: KLUTE, A., (ed.). Methods of soil analysis. 2.ed. Madison: American Society of America, 1986. Part.1. p. 331-361. 